\title{
Analysis of Classroom Practice in Engineering Graphics Teaching
}

\author{
Hua Chen ${ }^{1}$, Hao Yang ${ }^{2}$ and Jing Wan $^{3}$ \\ 1) School of Mechanical Engineering, University of Science and Technology Beijing, Beijing, China (chenhua@ustb.edu.cn) \\ 2) School of Mechanical Engineering, University of Science and Technology Beijing, Beijing, China (yanghao7212@sina.com) \\ 3) School of Mechanical Engineering, University of Science and Technology Beijing, Beijing, China (tywanjing@163.com)
}

\begin{abstract}
The engineering graphics is a required course for undergraduate students of engineering colleges. Classroom practice is an important channel for information exchange between teachers and students in the classroom teaching. In order to improve the effect of classroom teaching, we should optimize the classroom practice. In this paper, the attentions in the optimization of classroom practice were discussed by the classroom practice examples in engineering graphics teaching. Through the positive role of classroom practice, we should improve the students' intelligence and ability.
\end{abstract}

Keywords—classroom practice, classroom teaching, engineering graphics

\section{浅析工程图学教学中的课堂练习 \\ 陈华 杨皓 万静 \\ 北京科技大学机械工程学院, 北京, 中国}

摘＼cjkstart要工程图学这门课程是高等工科院校本科生的必修课。课堂练习是课堂教学中的一个重要环节, 是师生之间进行信息交流 的重要渠道。要提高课堂教学效果, 就要优化课堂练习。本文应用工程图学教学中的课堂练习实例, 探讨了在优化课堂练习时遵循的 设计原则。力求充分发挥课堂练习的积极作用, 促进学生的智力发展和能力提高。

关键词 课堂练习, 课堂教学, 工程图学

\section{1. 引言}

工程图学这门课程是高等工科院校本科生的必修课, 是一门重要的专业基础课。这门课程学习投影法基本理论, 培养绘制和阅读机械图样的能力及空间思维能力。课堂教 学在工程图学教学中起着重要的作用, 是学生学习知识的 主要途径[1]。课堂练习是课堂教学中的一个重要环节, 是 沟通教与学的桥梁。教师可以通过课堂练习对教学目标的 达成程度进行准确定位, 以便及时调整教学策略, 促进教 学质量的提高。同时, 课堂练习可以帮助学生进一步理解 课堂上所学的知识, 及时应用所学知识解决问题, 促进知 识的巩固及消化吸收 $[2,3]$ 。

\section{2. 课堂练习的优化}

但是很多时候由于制图课本来就比较难, 内容也比 较多, 但学时越来越少, 教师往往会在课堂上讲得过多,
即使有课堂练习, 也只是口头问答式的, 学生对教学内 容的理解不深, 以至于学生完成的作业准确率差, 失去 了作业巩固的效果。而如果学生能在课堂上实际作图, 有动手操练的机会, 效果就会好很多。教师应该如何优 化课堂练习, 充分发挥课堂练习的作用呢?

\section{1 注重时效性, 与课程特色相结合}

课堂教学是限定在一定的时间内的, 所以教师要注重 优化课堂练习, 提高练习的时效性[4]。

本课程在学习时要求所画视图必须满足三等关系, 要 进行实际的画图练习, 学生需要将题目画在练习本上, 才 能解题, 这样会浪费许多时间。我们在课堂练习时, 会把 题目一直显示在屏幕上, 学生只需画出对应的视图, 图中 各元素大致与屏幕上的题目对应即可, 而且要求学生必须 手工绘制, 不使用尺规, 既培养学生的手工绘图能力, 又 
在有限的时间内完成了课堂练习。

例如学习线面分析法时, 可以安排一道己知两个视图 补画第三个视图的课堂练习, 如图 1 所示。学生就可以在 练习本上仅绘制左视图, 还可以要求学生同时绘制出立体 的轴测图。

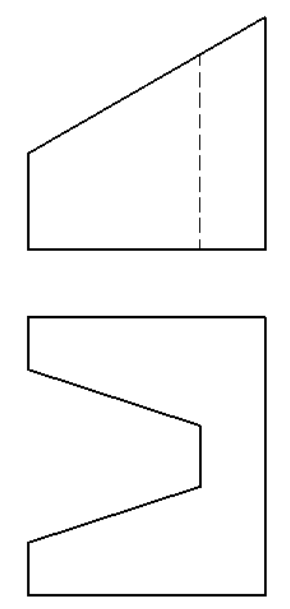

图 1 已知两个视图补画第三个视图

\section{2 具有针对性, 突出重点}

教学中的每节课都有非常明确的教学目的, 而课堂练 习就是为教学目的服务的。在制图课堂教学活动中, 课堂 练习要正确地把握本节课的重点和难点, 力争突出重点、 突破难点、明确所学。因此需要选择具有启发性、典型性 和针对性的习题, 专门针对这节课的教学内容而设计课堂 练习。为学生顺利掌握知识、形成良好的知识结构创设有 利的条件。

例如学习肋板的画法时给出一个补线练习, 如图 2 所 示, 其中包含了肋板未剖开和剖开的画法, 让学生通过课 堂练习, 理解并掌握这个知识点。
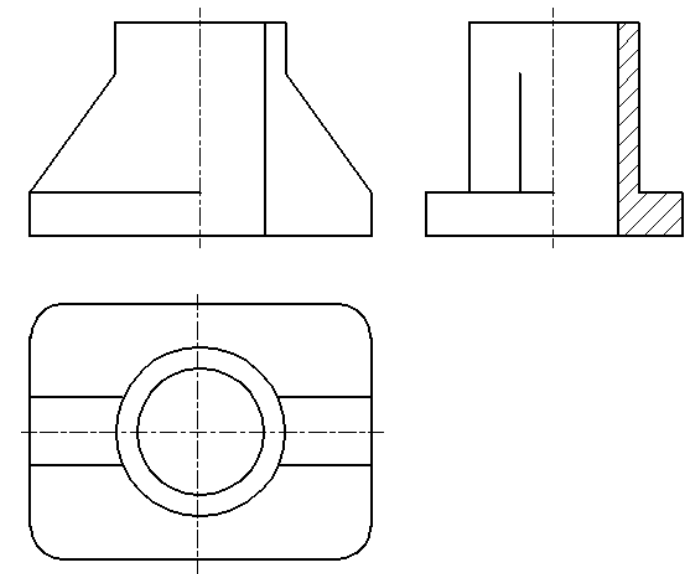

图 2 肋板的补线练习

\section{3 体现知识的连贯性, 注重反馈信息}

好的课堂练习既促进学生对课堂知识的理解和运用, 又能在知识的整个学习过程和体系中起到承前启后的作 用。为了能够更及时、更准确地反映学生的知识形成情况, 练习题的设计应能够促进教学信息的迅速、及时反馈, 更 早地发现学生学习过程中存在的问题, 便于教师掌握学生 的学习情况, 及时调整教学环节, 提高教学效果。

比如求空心圆柱的截交线是学生学习的一个难点, 学 生很容易出错。教师可以在这节课中设计一个课堂练习, 如图 3 所示。此练习题涵盖的知识点有前面学过的基本几 何体的投影以及本节课的求圆柱截交线的相关内容。学生 首先要理解空心圆柱的投影, 然后画出相应的截交线。这 样的练习既巩固了以前学过的知识, 又要应用本节课内容 解决问题。教师能够很容易地了解学生到底在哪个环节出 现了偏差, 掌握学生对知识的接受程度, 根据练习提供的 反馈信息调整教学。
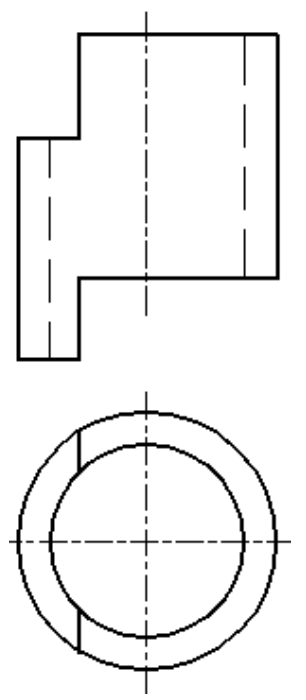

图 3 空心圆柱的截交线

\section{4 注意形式的多样性, 激活思路}

设计练习题时必须注意形式灵活多样, 灵活的课堂练 习有利于促进学生积极思考, 激活思路。制图课的课堂练 习应恰当运用如选择、填空、判断、补线、作图等形式, 针对不同的知识点可以安排不同形式的练习, 发挥每种练 习的独特作用, 从而提高课堂教学效果。

比如学习剖视图的画法时, 可以将容易出现的错误画 法或者需要重点理解的地方巧妙地编到题目中, 用选择题 的形式给出如图 4 所示的课堂练习。已知立体的主视图和 俯视图(图 4a), 选择用全剖视图表达主视图的正确选项(图 4b)。画剖视图的注意事项在此题的几个错误选项中明确地 展示出来, 以突出剖视图的正确画法。 

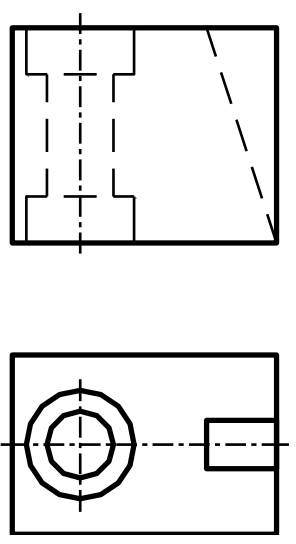

(a)

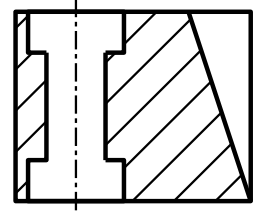

(1)

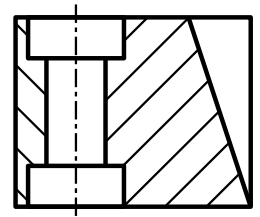

(3)

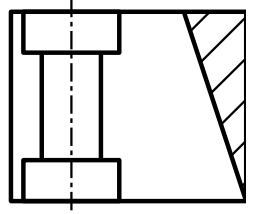

(2)

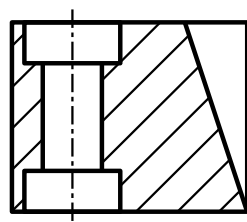

(4) (b)

图 4 用全剖视图表达主视图

\section{5 增加趣味性, 体会学习的乐趣}

可以将说、写、画、评、游戏等有机融合起来, 设计 练习的趣味性, 让学生在练习中产生愉悦的情感, 体会学 习知识的乐趣。学生学习的兴趣浓厚, 自然学习效果也就 显著。

比如在学习圆柱的截交线这一节可以设计一个穿孔练 习。让学生构想出一个实物的三维模型, 使其三个方向的 外形轮廓能刚好分别通过图 5a 所示的三角形、圆形和正方 形孔。通过这个穿孔练习, 可以让学生体会到思考与想象 的乐趣。在思考过程中学生需要充分发挥空间想象力, 把 空间想象和投影分析相结合构思空间物体, 并进行反复修 正, 直到构想出图 5b 所示的立体。自己通过想象构想出立 体的同学会有一种成就感, 也会对后面要学习的组合体的 构形设计产生浓厚的兴趣。此时可以应用本节课学习的知 识将这个立体的三视图画出来, 如图 5c 所示[5]。

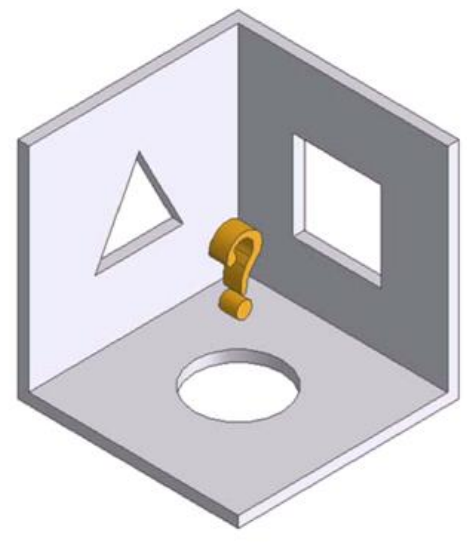

(a)

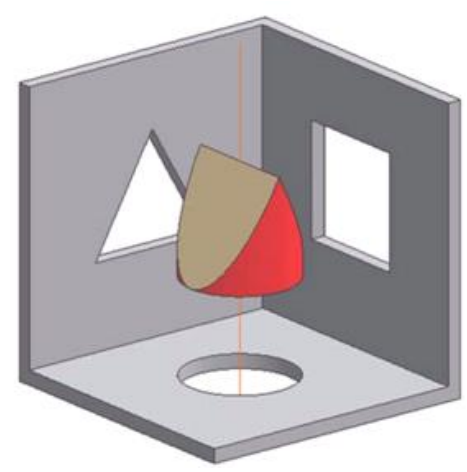

(b)
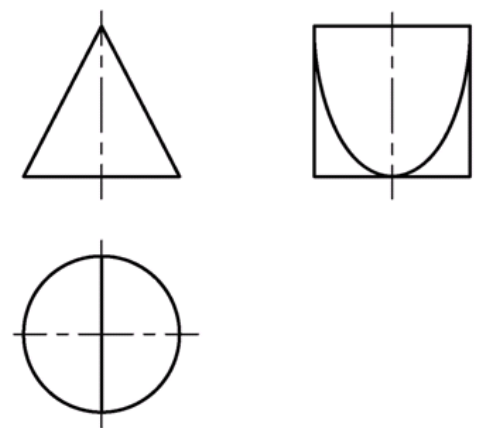

(c)

图 5 穿孔练习

又如在讲解主视图选取原则时, 可以给学生出一个灯 谜。首先在屏幕上显示图 6a 所示形状, 令学生打一日常用 品。当无人答对时, 再相继显示图 $6 \mathrm{~b}$ 和图 $6 \mathrm{c}$, 激发学生的 思维不断活跃。当学生看到图 $6 \mathrm{~d}$ 时, 所有人都能猜到谜底 是茶杯, 也能深刻理解主视图选取时的特征明显原则和自 然放置原则。 


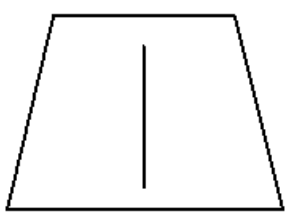

(a)

(c)

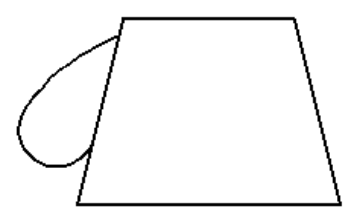

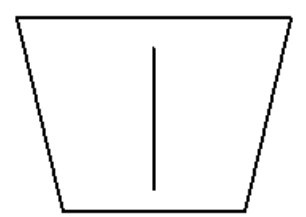

(b)

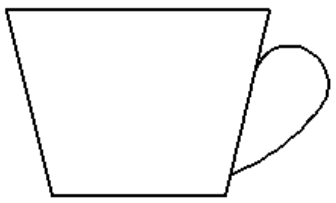

(d)
图 6 猜灯谜

\section{6 具有层次性, 遵循循序渐进原则}

课堂练习的设计要具有层次性, 遵循学习知识的循序 渐进原则。练习要根据所学内容由易到难, 由简到繁, 逐 步深化提高。这样可以减少学生的学习负担, 避免造成学 生的心理疲备。学生在已有知识结构的基础上, 逐步地理 解接受新知识, 再进一步地应用已有的知识解决问题, 直 至达到创新发展的新阶段, 学生的知识系统也就日趋完善 健全。

比如组合体的读图是比较难的, 在讲解了读图的一般 方法和步骤后, 可以先给出一个简单的组合体读图练习, 其中没有任何截交、相贯的内容, 仅是几个形体的叠加和 挖切(如图 7a), 其次给一个带有圆柱正贯的简单组合体(如 图 7b), 然后给一个有相切和圆柱截交的简单组合体(如图 7c), 最后给一个包含截交、相贯、相切的复杂组合体(如图 $7 \mathrm{~d}$ )。学生从最基础的练习出发, 然后逐步加深, 层层递进, 将已有的知识串联起来, 从而解决了较复杂的组合体的读 图问题。这种分步递进的想法也是解决组合体读图问题的 基本作图方法。

\section{3. 总结}

在课堂教学中, 课堂练习可以加强师生互动, 是师生 之间进行信息交流的重要渠道。优化课堂练习不仅可以使 学生处于一种活跃的思维状态, 加强记忆, 加深理解, 提 高听课效率, 而且对学生智力的发展和能力的提高也会起 到十分重要的作用。我们在教学中要充分利用课堂练习这 一重要教学组成部分, 从而达到开发学生智力、启迪学生 思维的效果, 努力培养富于思考、勇于实践、敢于创新的 人才。
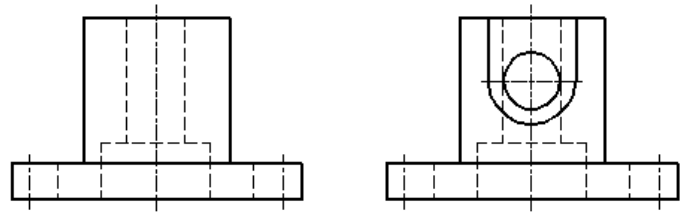

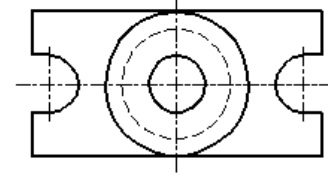

(a)
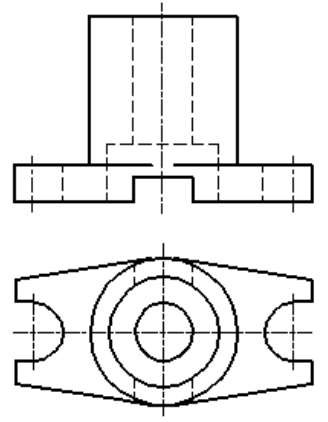

(c)

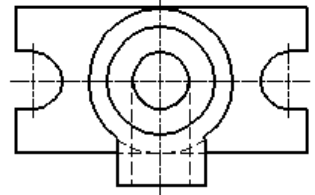

(b)
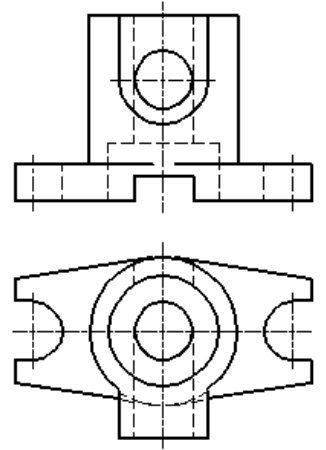

(d)
图 7 组合体读图

参考文献(References)

[1] Feng Guo, Lijie Guan and Chunhua Wang, "Research and practice on teaching methods and measures of modern engineering graphics," Journal of Donghua University( Natural Science), vol. 34, no. 3, pp. 376-379, 2008.

[2] Wei Wang, LiZhen $\mathrm{Xu}$ and Yisheng Dong, "Research for classroom instruction ideal and teaching method," in Second International Workshop on Education Technology and Computer Science (ETCS), vol. 2, Wuhan, March 2010, pp. 547-550.

[3] Mingshun Li, "Study on students' creative thinking cultivated by open classroom teaching method," in International Conference on Education and Management Technology (ICEMT), Cairo, November 2010, pp. 376-379.

[4] Dong He, "Rationally design of classroom exercises to enhance teaching effectiveness," journal of nanchang college of education, vol. 26, no. 6, pp. 111-113, 2011.

[5] Zhongqiang Dou, Design and expression of industrial products (Second Edition). Beijing: Higher Education Press, 2009. 